\title{
DAR LA PALABRA O DE LA INSOLVENCIA DEL YO*
}

\author{
Humberto Giannini \\ Universidad de Chile
}

\begin{abstract}
Resumen: Toda comunicación real ocurre como un modo de vincularse de un sujeto a otro(s). Al sujeto que propone la vinculación lo llamaremos 'sujeto testimonial'. Y aunque en la mayoría de los casos este sujeto no está explícito, es justamente el significado de su acción lo que se comunica y aquello en virtud de lo cual los sujetos actuantes convergen hacia alguna referencia.

Se ponen como ejemplos las acciones comunicativas de prometer y dar la palabra, ambas con sujeto testimonial explícito.
\end{abstract}

Palabras clave: comunicación, sujeto testimonial, acción, significado, convergencia, referencia.

Recibido: junio 2011; aceptado: septiembre 2011.

Humberto Giannini (1927). Premio Nacional de Ciencias Sociales y Humanidades (1999). Doctor Honoris Causa, París VIII. Profesor emérito de la Universidad de Chile (gianniniluz@mi.cl).

* Este texto es el resultado de la investigación desarrollada en el proyecto Fondecyt № 1110811, actualmente en curso: "El horizonte ético-político del perdón y la promesa. Claves de una ética del conflicto". En el proyecto Fondecyt y en el trabajo actual participan como colaboradores los doctores Juan José Fuentes, Eva Hamamé y Nicole Gardella. 


\title{
TO GIVE ONE'S WORD OR THE INSOLVENCY OF THE SELF
}

\begin{abstract}
Every real communication happens as a way of linking a subject to another(s). We call 'testimonial subject' to that one who proposes the link. And though in most cases this subject is not explicit, it is precisely the meaning of his/ her action what is communicated and whereby the acting subjects converge to some reference.

We take as examples the communicative actions of promising and giving the word, both with explicit testimonial subjects.
\end{abstract}

Keywords: communication, testimonial subject, action, meaning, convergence, reference.

Received: June 2011; accepted: September 2011.

\section{Comunicar es una acción}

\section{6}

la comunicación; al menos por esto: porque toda cuestión filosófica está saturada, por decirlo así, de la omnipresencia de la palabra" ${ }^{\prime 1}$ o, dicho de otro modo, porque solo con la palabra el ser humano puede tocar los grandes abismos en que parece sostenerse el ser del Universo, la vida y el mundo de la humanidad.

Hay, pues, una deuda de la filosofía con su propia sustancia expansiva: la comunicación; una deuda de reconocimiento, de revaloración. Lo que queremos decir como punto clave de este estudio, es que la comunicación no se identifica con una estructura semántico-sintáctica que pueda estudiarse en su ser propio en el ámbito cerrado de una ciencia: la lingüística, por ejemplo. ¿Por qué? Porque no es estructura ni mera referencia; porque esencialmente es actividad, acción. Y una acción connatural a la vida humana: aquella por la que el ser humano fue definido en el pasado no sólo como zoon logon echon o animal que posee la palabra; sino también como 'animal histórico-social' y, por lo que a nosotros concierne ahora, sobre todo, como 'sujeto moral'.

Nuestra tarea primera tendrá que ser, entonces, delinear los caracteres propios de una acción en general, a fin de distinguirla, por una parte, de lo que se entiende hoy como 'movimiento' en el ámbito de la

\footnotetext{
${ }^{1}$ Humberto Giannini (1984).
} 
vida mental, es decir como acto intencional, y por otra parte, para distinguirla también tanto de los movimientos reflejos de los seres animados que estudia la biología como de los movimientos mecánicos de los cuerpos inanimados.

Luego, cuando tratemos de la acción en su especificidad comunicativa, centraremos nuestra atención en el campo de lo que llamamos la 'corp-oralidad ${ }^{2}$ del lenguaje'. Hay una razón fundamental para hacer esta distinción, pues, aun cuando es cierto que sentarse a escribir y ponerse a escribir son genéricamente acciones, es evidente que desde el punto de vista específico de la comunicación son solo potencialmente acciones comunicativas. Y que no lo son realmente mientras no llegan, si es que llegan, al lector determinado o anónimo al que el escrito va dirigido o quien por azar lo recibe ${ }^{3}$.

El supuesto que nosotros manejamos es que el lenguaje corp-oral existe como fundamento de la vida asociada ${ }^{4}$; que su actualidad solo ocurre y circula en la interacción directa entre los seres humanos. Lo que significa con evidencia que en el escenario civil, en cada acción comunicativa real, in $a c t u^{5}$, concurren un agente que pro-pone y un destinatario que responde, y que ambos se correlacionan en virtud de la acción que los vincula ${ }^{6}$. Es, pues, esta vinculación con el otro lo propio de la 'acción comunicativa'. Y llamaremos 'referencia' al objeto implicado en virtud de tal acción transitiva?.

Para no perder de vista la extensión y límites de nuestro propósito, debemos habituarnos a desustantivar mentalmente el término 'comuni-

${ }^{2} \mathrm{O}$, mejor, del lenguaje como 'corp-oral'. Usamos esta expresión simplemente como apoyo para recordar que se trata de una acción en la que participan tanto el cuerpo significante como la 'boca parlante (orans)'.

${ }^{3}$ Por ejemplo: las obras del 'Aristóteles perdido' fueron en parte descubiertas varios siglos más tarde. Es posible imaginar que jamás hubiesen llegado a ser conocidas y que así nunca pudieran haber sido comunicadas ni difundidas.

${ }^{4}$ De la interacción oral como fundamento de la vida cotidiana nos ha hablado Platón en la antigüedad, Condillac en el siglo XVIII, cfr., Essai sur l'origine des connaissances humaines (citado por Derrida, 1990), y Lévinas (1987) en el siglo XX.

${ }^{5}$ In actu: actual, que significa aquí también actuante.

${ }^{6}$ Platón en la antigüedad hizo la primera defensa filosófica de la palabra hablada y del diálogo como formas esenciales de la actividad filosófica. En nuestros tiempos, Lévinas ha declarado que 'el discurso es la plenitud de todo discurso' (1987).

${ }^{7}$ En términos gramaticales: al objeto (complemento) directo. 
cación' y apuntar sin trámite a la acción de comunicar ${ }^{8}$; determinación que nos arrancará de antemano del plano de las estructuras abstractas, sin sujeto, volantes, como a las que se han adscrito con variado énfasis las diversas formulaciones del estructuralismo. Comunicar es una acción.

Este intento para mostrarlo arrastra, además, algunas implicaciones epistemológicas y éticas. La más importante: espanta el fantasma del solipsismo que ha estado rondando a la filosofía moderna (desde Descartes a Husserl). Aleja, por otra parte, del sensualismo lógico (Wittgenstein) que blindaba la experiencia contra realidades epistemológicas y éticas innegables.

El precio que se paga por esta liberación es admitir una situación paradójica inseparable de la acción comunicativa. Y la paradoja consiste en que este hecho de comunicar no puede limitarse, por principio a ser solo una acción. O más explícitamente: para ser una acción realizada - actual, entonces_- debe ser interacción.

$\mathrm{Si}$ alguien decide en su fuero interno vender su casa, esta decisión no es todavía una acción sino un proyecto. Decíamos: 'solo un acto intencional'. Pero, desde el momento en que ofrece en venta su propiedad, está realizando una acción comunicativa, esto es, una interacción con otro sujeto.

Volviendo a lo nuestro, la acción actual de comunicar ocurre solo cuando existe otro sujeto que entiende el significado de mi propuesta o proposición, y responde a ella, incluso con el silencio. Así, la acción comunicativa instala un principio de dualidad: debemos contar con el otro. Volveremos sobre esto. Por ahora intentemos separar la acción comunicativa, por una parte, de la acción en general y, por otra parte, tanto de los actos psíquicos (intencionales) como de los movimientos físicos, que no son propiamente acciones.

\section{Del acto a la acción}

Para empezar nuestra tarea de deslinde entre 'acto de conciencia' (intencional) y 'acción', examinemos el vínculo íntimo, por cierto, entre un acto psíquico cualquiera — digamos, el deseo de algo- y una ac-

${ }^{8}$ Con 'desustantivar' queremos dar a entender la disposición a devolver a la comunicación su función verbal, esto es, queremos invitar al lector a pensarla como acción (y no como una representación sustantivada de una acción), que solo cabe cumplir en primera persona singular (un yo) en el tiempo que le es presente (un ahora). Solo así es una acción comunicativa y no una representación de ella por un yo que se la está representando. 
ción, no necesariamente comunicativa, que se ejecuta con el propósito de real-izar tal deseo. El acto denota un dirigir de cierta manera 'la mirada interior' a algo real, imaginario o meramente posible. Por ejemplo, a alguien a quien deseamos ver. Es evidente que este mero apuntar no cubre en absoluto la distancia real que me separa de la cosa deseada. $\mathrm{Y}$ esta es una de las razones por las que se le ha llamado 'acto intencional'. Es decir, por el hecho de que a la cosa real deseada, en cuanto es solo mentalmente deseada, no le afecta en absoluto en su ser que un sujeto en su fuero interno la desee, la recuerde, la haya olvidado ${ }^{9}$, etc. Y definitivamente, no tendría por qué afectarla si ese deseo no intentara ${ }^{10}$, cuando se ha vuelto, llamémosle así, deseo-dolor ${ }^{11}$, liberarse de sí mismo; es decir, si no clamara otro tipo de proximidad a las cosas a las que la conciencia, en sus actos intencionales, meramente apunta. Podría decirse incluso que este deseo es una suerte de clamor por la cosa misma. Así, atravesar el Amazonas para llegar hasta el ser deseado ${ }^{12}$ no es ya un acto de conciencia sino una iniciativa que va apaciguando o absolviéndome de ese 'deseo-dolor' que tengo, en este caso, de llegar a ver a alguien. Detengámonos aquí.

¿Qué pasa cuando se pasa del acto a la acción? ¿Y cómo pasa? No es siempre tan fácil determinar el punto preciso del 'salto'13. Sin embargo, es esencial determinar este 'salto', puesto que en él se nos revela el poder de iniciar algo desde sí, propio de la acción de un agente práctico.

Se suelen proponer diversas secuencias de aproximación para hacer reconocible, puntualmente identificable, el momento del tránsito desde el acto subjetivo de querer algo, a la acción por la que el 'de-

${ }^{9}$ No es tan claro que el acto no afecte al 'objeto' percibido cuando 'lo percibido' es otro sujeto: un sujeto que a su vez nos percibe.

${ }^{10} \mathrm{El}$ deseo de algo es, como decíamos, un acto intencional entre otros. Sin embargo, constituye uno de 'los motivos' más fuertes de 'la salida hacia el mundo' de la subjetividad (es lo apetecible lo que mueve el apetito, como decían en el Medioevo).

${ }^{11}$ Llamamos deseo-dolor a esa clase de deseo que urge por su satisfacción al punto de hacerse insoportable.

$12 \mathrm{O}$ una secuencia de acciones. Atravesadas por un mismo propósito, esto es, todas ellas guiadas por un solo proyecto, por un solo final, v.gr. volver a ver a quien estoy deseando reencontrar.

${ }^{13}$ La expresión 'salto’ es de Kierkegaard (1956), p. 104. 
seo' - hecho interior - rompe el misterioso cerco de la subjetividad e 'irrumpe' en pos de aquello que quiere, como el Segismundo de Calderón (Calderón de la Barca, La vida es sueño, jornada III, escena II, 1950).

En este intento de aprehensión teórica del 'fenómeno', la psicología o la filosofía tradicionales suelen llegar, por un recorrido subterráneo hasta algún 'movimiento' interior considerado como límite definitivo de esa moción, por ejemplo: el de la resolución, última parada interior, al parecer, antes del 'salto' resolutivo.

Sabemos, sin embargo, que una resolución ya tomada puede aferrarse todavía al tiempo interior de la conciencia; que es una 'estación' en la que siempre cabe quedarse y esperar todavía otro tren, una resolución que suele debilitarse o venírsenos por tierra justamente cuando estábamos a punto de atravesar el abismo ${ }^{14}$.

$\mathrm{Al}$ parecer, en este tránsito, que a veces se asemeja a un parto, consiste la acción humana: en trascender, en hacer real el querer, el proyecto, articulándolo definitivamente a las vicisitudes del mundo. Paul Ricoeur ha abordado con sumo rigor el estado actual del problema (Ricoeur, 1986).

\section{El 'desde sí'}

En nuestros tiempos, Arendt (2003) lo ha subrayado con energía: la acción es un verdadero inicio. Y lo es en cuanto inaugura no solo una nueva serie de secuencias causales ${ }^{15}$, sino también una nueva serie de contingencias y por último una nueva serie de casualidades. Lo que importa destacar ahora es que con la acción se inicia siempre algo nuevo en el mundo humano. Es en virtud de la acción que a su agente lo llamamos 'sujeto humano'. Aquel ente que se mueve desde sí.

Pero, ¿qué significa 'desde sí? ¿Significará, acaso, una fuerza que se dispara, sin otra condición que la de no ser consecuencia y efecto de una fuerza externa/anterior? El agente que se mueve desde sí, ¿es, entonces, agente ciego, sin rumbo en su movimiento, sin sentido? ¿Uno que cuando se mueve no se dirige a mover o remover nada?

14 'Del dicho al hecho hay mucho trecho', suele recordarnos la sabiduría popular.

${ }^{15}$ Cfr. Humberto Giannini (2007), cap. XIII. 
Una respuesta afirmativa resulta totalmente insatisfactoria apenas la examinamos desde el ámbito de la acción comunicativa, pero, sobre todo, desde la experiencia moral.

La espontaneidad del desde sí no es arbitraria, 'voluntariosa', ni gratuita. El desde sí es el origen de un movimiento que ya se experimenta y se proyecta al mundo como deseo de lo otro, de lo deseable.

En caso de que no supiera hacia qué ni hacia dónde se mueve, ¿cómo podría ser desde sí? ¿Y cómo podría ser este un sujeto susceptible de determinaciones éticas?

Volvamos ahora a lo que veíamos hace un momento: es posible que por el mero acto de desear ni siquiera se tome la resolución de alcanzar aquello que se desea. Recién empieza a configurarse como proyecto cuando ese acto en cierto modo trasmite su urgencia a la sensibilidad del cuerpo y la despierta para el mundo. Es a partir de esta suerte de 'contagio' que el ser apetente rompe el cerco, por así decirlo, de la subjetividad y, como nauta inexperto, empieza a tantear la espacialidad del mundo y a actuar sobre lo que este mundo le presenta 'a distancia'. A nuestro parecer, no era impropia la concepción aristotélica de causa final en contraposición a la causalidad mecánica. El desde sí es sujeto porque al moverse ya es proyecto de ser, es dirección a lo otro, apetito de lo otro. En definitiva: es a este 'móvil' que pretendió hacer eso que ahora está haciendo, esto es, ir desde sí hacia algo diverso de sí; es a tal ente que llamamos un móvil que actúa, un sujeto.

Podemos decir finalmente que es por este acto unitario que sabe y propende hacia eso que ahora está haciendo en el mundo, que el sujeto actuante se experimenta como fuente y pro-yección de sí y del movimiento que lleva a cabo; que se experimenta como unidad de ser. Éticamente, como responsable.

Este es el supuesto de la vida comunitaria en cuanto tal. Supuesto ontológico, pero ético a la vez, que permite tratarnos unos a otros como sujetos y aquilatar en cada situación el valor de nuestras acciones ${ }^{16}$.

Para comprender a fondo este supuesto, la concepción pragmática del lenguaje ha sido sustancial. Y en este sentido, ha representado una de las grandes innovaciones del pensamiento contemporáneo, que inicia Reinach - y por otras vías, Austin y Searle-. Esta concepción

${ }^{16}$ Según este supuesto lo bueno y lo malo son categorías de la acción y solo analógicamente de las operaciones de los instrumentos y enseres. 
pragmática del lenguaje establece que el decir es actuar. Y que esta acción involucra necesariamente una relación al otro. Permitió, además, a partir de la segunda mitad del siglo pasado, el reencuentro entre posiciones filosóficas tradicionalmente contrapuestas: la fenomenología y el pragmatismo anglosajón (D'Agostini, 2000).

Pero ha faltado, sin embargo, un impulso sostenido que radicalice las consecuencias que cabe derivar de esta nueva concepción del lenguaje, sobre todo, en el plano de la reflexión ética.

\section{La comunicación es acción vinculante de un desde sí a otro desde sí}

El lenguaje corp-oral es acción. Este es el núcleo de nuestro punto de partida. Ahora, en cuanto acción comunicativa - nuestro tema específico-, no habrá que perder de vista su rasgo diferencial: ser la iniciativa por la cual un sujeto actual —el que habla ahora ${ }^{17}$ - se vincula, mediante la palabra, a otro sujeto, a fin de converger hacia alguna cosa del mundo común.

Bien puede haber acción ${ }^{18}$ sin experiencia del otro, pero no puede haber acción comunicativa sin experiencia del otro. Ahora bien, tampoco puede haber experiencia del otro sin que esta sea bajo la forma de una interacción comunicativa. Es solo en este sentido que tenemos derecho a hablar de 'una experiencia real del otro'. La que no cabe explicar por medio de conceptos u operaciones intelectuales: al otro lo experimento directamente como otro 'desde si', en el instante en que nos encontramos en la mirada mutua ${ }^{19}$. La experiencia del otro propia de la comunicación es, como lo hemos sostenido en otro lugar (Giannini, 2007), sui generis, inconmensurable con aquella por la que llegamos a conocer los objetos.

${ }^{17}$ Sobre el término 'actual' hay que insistir en que se trata siempre del sujeto (ontológico) que en 'este momento mismo' se está expresando.

18 Quizá esta acción meramente individual sea mejor nombrada bajo el concepto de 'conducta'.

19 "Si a tu ojo le dijeras como si se tratara de un ser humano: "mírate a ti mismo'. ¿Qué crees tú que se le estaría aconsejando? ¿No se le aconsejaría acaso mirar hacia eso mismo en que, al mirarlo, el ojo logra verse a sí mismo? Evidentemente, contesta el joven-. Es solo mirando otros ojos y lo que hay de más excelente en ellos - la pupila en que se ven a sí mismos-, entonces, que podrán conocerse a sí mismos" (Platón, Alcibíades, p. 16). Una de las tantas imágenes platónicas acerca del conocimiento de sí a través del otro. 
Dicho del modo circular en el que únicamente puede decirse: en la experiencia que se tiene del otro, quien está ante mí es, por lo mismo, aquel ante quien yo estoy como ante otro que me está percibiendo cuando lo percibo. Percibir al otro es ya comunicarse con él en una relación de absoluta reciprocidad y actualidad.

Es en virtud de esta experiencia de reciprocidad ontológica, anterior tal vez a la experiencia de los objetos y fenómenos del mundo, que entramos en el territorio de la interacción comunicativa y también en el territorio de la experiencia moral

Hay que decir por último que la tarea de destacar la importancia de la acción comunicativa, en cuanto acción, es algo sumamente dificultoso, puesto que es aquello que, en general, se omite en el concreto trato comunicativo. Hay varios motivos que explican este silencio, pero ninguno nos parece suficiente para silenciar una reflexión filosófica sobre ellos.

Los motivos. El primero: ante un imprevisto, ante un peligro inminente, las miradas suelen volverse sobre los objetos, las cosas, los fenómenos que se nos vienen encima, y no sobre el vínculo que un sujeto cualquiera entabla con nosotros para advertirnos (;fuego!). Es obvio que lo que se quiere hacer es poner en guardia contra el peligro y que es en virtud de esa intención que atendemos solo a la urgencia 'objetiva', de 'lo que se dice', esto es, directamente a la eventualidad que está en juego cada vez.

Un segundo motivo: hay situaciones (descritas por los enunciados) que no parecen tener necesidad de que alguien 'sostenga' la actualidad de su verdad. Por ejemplo: lo que se sabe de la regularidad física del mundo, de la necesidad de los principios, lo que se dice de la obligatoriedad moral, que parece justificarse por su propio sentido ético, 'universalmente válido'. Lo con-sabido, lo rutinario ${ }^{20}$.

Solo parece salvarse de la obviedad de ser siempre así, lo contingente, lo que estamos llamados a negar o a afirmar desde nuestra propia contingencia y desde una temporalidad que estamos obligados a declarar y a asumir como testimonios.

En otros escritos hemos examinado diversos aspectos de la actualidad comunicativa. Ahora nos interesa destacar el hecho de que sea

${ }^{20}$ Lo que según Heidegger repetimos, y volvemos a repetir, simplemente porque 'se dice'. 
en esta actividad cotidiana donde el ser humano alcanza también la experiencia originaria de su dignidad.

Es en el mundo donde nos encontramos con los otros. No existe otro lugar de encuentro. Pero, a su vez, este mundo común — de los encuentros y desencuentros cotidianos - tiene actualidad y presencia solo en virtud de la acción comunicativa. Dirigirse con la palabra a otro ser humano es, también y necesariamente, abrir o rescatar una relación con el mundo en el instante mismo en que se habla; rescatar algo del ser, algo sumergido por horas o por siglos en el olvido. En virtud de la comunicación, no somos en el mundo sino que nos citamos en él.

\section{Dar la palabra}

Importa, ahora de un modo decisivo, recordar lo que decíamos antes: que cuando hablamos de acciones como 'prometer', 'prohibir', 'ordenar', el sujeto actuante, por el hecho de declararlo, hace lo que está diciendo; esto es, al decir 'te prometo', ya ha prometido; al decir 'te prohibo' ya ha prohibido algo. Tal es su acción. Y a la cual responde con alguna acción correlativa el sujeto al que fue dirigida la promesa o la prohibición ${ }^{21}$.

No cabe afirmar, entonces, que son 'meras palabras' aquellas por las que un sujeto queda vinculado a otro. $\mathrm{O}$ mejor, hay que afirmar que son meras palabras solo para quien las ha expresado sin el propósito de cumplir lo que ha prometido, o sin querer entregar en el futuro aquello sobre lo cual ha dado 'su palabra'.

Es decir, salvo que lo que proponga un sujeto sean para él meras palabras, en eso que propone, al decirlo con integridad, se declara portavoz de sí mismo respecto de la vinculación que propone al otro sujeto.

Queremos llegar a este punto: afirmar que en cada acción comunicativa el sujeto que tiene ahora la palabra, al hablar y por el hecho de hablar, no solo se declara portador de alguna verdad — pequeña o grande - que ahora descubre, rescata y expone (por ejemplo, cuando enuncia cualquier cosa), sino que $-\mathrm{y}$ es lo que ahora nos importa destacar - en todas sus expresiones, en cualquiera de ellas, se declara portavoz de sí mismo, portavoz de lo que realmente está siendo y pretendiendo hacer en la actual vinculación que ahora abre hacia otro suje-

${ }^{21}$ Bajo el supuesto que haya percibido la acción a él dirigida. 
to. En otros términos: que la suya es una suerte de presentación de sí y no una re-presentación descomprometida o distractora que exhibe para ocultarse.

Es lícito afirmar, entonces, que quien habla se vuelve testimonio de sí. Y que, por lo mismo, y en todo momento, este acontecimiento de ex-ponerse en la palabra, es también inmediata ocasión de que cada cual use su condición testimonial para sus propios fines, y pueda convertirse también, entonces, en un falso testimonio. Por eso, el cuidado de no falsificar la propia presencia en el encuentro con el prójimo resulta ser un principio inseparable de la autenticidad y de la dignidad humanas. Por otra parte, el falso testimonio que da un sujeto de sí deja al otro 'fuera' de una comunidad de la que se creía partícipe. Y en esto consiste el sentimiento de la dignidad lesionada, propio de la ofensa. Ambas experiencias — la de la dignidad y la de la ofensa — están a la base del encuentro con el otro, esto es, de la experiencia moral.

\section{Dar la palabra, prometer y jurar: Ser testimonio}

Hemos llamado al sujeto ontológico de toda comunicación 'testimonio de sí', esto es, garante del vínculo que propone a otro sujeto.

Ahora bien, respecto de lo que se dice, ¿qué fuerza de convicción diversa de la palabra que se da o de la promesa que se hace, agrega el juramento?

A causa de la paulatina secularización del lenguaje, el juramento ha llegado a ser como la estatua de algún dios antiguo, 'un monumento' severamente trunco y dañado por el tiempo. Sin embargo, en nuestro uso banalizado de la palabra, fuera del énfasis que se puede poner al pronunciar el juramento, no parece diferir de los pocos modos de dar explícita y manifiestamente testimonio de lo que decimos.

Ciertamente, el juramento dijo más y fue más en el pasado que todas nuestras expresiones actuales. Por ello Émile Benveniste (1983, p. 304) lo presenta como una ordalía, esto es, un rito en el que le iba la vida al sujeto juramentado.

Sabemos que se llamaba 'testigo' (martyr, en griego), a quien, habiendo presenciado algo, no puede ya negarlo sin negarse a sí mismo. De esta manera el testigo se hace rehén de la verdad que ha experimentado, hasta el punto de inmolar la vida por ello ${ }^{22}$.

${ }^{22}$ Sobre el martirio, E. Castelli, "Introduzione”, 1972, pp. 23-30. 
Pero nosotros ahora queremos referirnos no al testimonio de lo que se ve o se escucha en el mundo, sino al testimonio de lo que somos verdaderamente en nuestra vinculación con los otros, al testimonio de nuestra propia veracidad.

Adelantemos un tropiezo no menor: una cosa es ser veraz, y otra más difícil de justificar es la de ser nosotros mismos garantía de esa veracidad. El medioevo sospechaba también de esta total autonomía ética del sujeto profundo (Diabolus intus agit).

Examinado en su perspectiva histórica, el jurar fue una acción comunicativa que, al menos en su origen cristiano, tuvo el carácter de una ceremonia ritual. Y suponía tres actores: El primero es quien decía 'juro' y, al hacerlo, por esta acción de jurar invocaba la presencia de Dios, él mismo testigo interior del testimonio que da de sí un ser humano mediante el juramento. La otra presencia entonces era la de Dios, que además, era el Juez ejecutor del castigo en el caso de un falso testimonio. El tercer participante era, se comprende, el destinatario del juramento.

Pero en nuestros días, no es grande la diferencia que guarda el juramento con expresiones tales como 'dar la palabra' y 'prometer' ${ }^{23}$. A estas últimas dedicaremos ahora nuestra atención.

Volvamos, por un momento, al punto de partida:

Toda acción comunicativa es un vínculo pro-puesto por el sujeto que 'tiene la palabra', al sujeto a quien va dirigida. Es a este primer sujeto que 'tiene la palabra' al que llamamos 'sujeto testimonial' para diferenciarlo del sujeto gramatical interno a la referencia ${ }^{24}$.

¿Qué acción cumple quien 'da su palabra' a propósito de algo que ha dicho? ${ }^{25}$ Ante todo, ¿se puede 'dar algo' que por principio se

${ }^{23}$ Independiente del sentido solemne que tiene en instituciones como el Ejército o la masonería, en la cultura popular sobrevive la costumbre de enlazar el índice con el pulgar de la mano derecha, formando una especie de cruz que el sujeto que jura besa en señal de estarlo haciendo ante el testimonio de Dios.

${ }^{24}$ En una estructura gramatical puede faltar el sujeto (en los verbos impersonales, por ejemplo); pero jamás, explícita o implícitamente, el sujeto testimonial. Así, el enunciado 'Está lloviendo'-que no parece tener sujeto gramatical- descansa también en un sujeto testimonial que lo enuncia.

25 'Dar', 'ceder la palabra', es un precepto básico de la reciprocidad en el trato entre iguales. Nosotros no nos referiremos aquí a tal precepto, sino al hecho de que el mismo sujeto que tiene la palabra suele 'darla' a otro, en garantía de lo que dice. 
vuela de los labios, 'se esfuma' y no permanece para nadie? (Ricoeur, 1986).

Habría que detenerse en esta caracterización de la palabra oral como volátil. Digamos por el momento que parece legítimo el asignarle tal condición solo en cuanto fenómeno acústico. En cambio, el verbo, la palabra, que preside cualquier comunicación oral, no es un fenómeno, ni menos, representación o idea de un fenómeno; es la acción de un sujeto singular, y como tal se prolonga narrativamente mediante el vínculo que crea $^{26}$. Pero, es claro, ella no afecta directamente a cosa alguna del mundo. $\mathrm{Su}$ sentido ${ }^{27}$ es pro-poner a otro sujeto un modo de converger unánime hacia algo. Es, por tanto, un envío vinculante de un 'desde sí' ante otro 'desde sí'. De esta manera, lo propio de la acción comunicativa es la correlación y no la fugacidad. Porque no hay ningún modo de ser 'presente' ante otro sujeto que no sea en virtud de la palabra actuando ${ }^{28}$ como verbo; concretamente, como la acción de un sujeto ante otro sujeto.

Es a la integridad de la entrega de sí en la vinculación que se propone al otro, es a la fiabilidad en 'la palabra que se da', a la que suele asignársele el nombre de 'veracidad': 'Veraz' es quien es tal como se ex-pone en lo que expone. Y este es el punto difícil de verificar intersubjetivamente.

Como lo han reconocido muchos filósofos, con este término se delimita una categoría exclusivamente ética ${ }^{29}$. Quisiéramos adherir a este criterio, pero no para reducir su importancia a una consideración parcial y subjetiva - la de la veracidad de cada cual en cada caso-, sino precisamente para transformarlo en un criterio general de la intercomunicación: la veracidad es una categoría de la comunicación. Y es allí y solo allí donde se deja percibir. Por esta misma razón, el tema de la veracidad ha sido un problema insoluble para el subjetivismo moderno.

El razonamiento modelo del subjetivismo moderno - el cartesiano - parte con el intento de desplegar una duda radical ${ }^{30}$ : Duda de la

${ }^{26}$ Narrativamente, no por relación causal; también la acción se antecede a sí misma, pero no causalmente.

27 Es lo que llamaremos su 'intención abierta, declarada': su sentido común.

${ }^{28} \mathrm{U}$ otro significante corp-oral: un gesto, una mirada, etc.

${ }^{29}$ Y no epistemológica (Hume, Leibniz, y en tiempos más recientes, Jaspers).

${ }^{30}$ Así lo muestra con nitidez y patetismo la primera de las Meditaciones metafisicas de Descartes. 
existencia de las cosas, del prójimo, de Dios, de sí mismo. Como sabemos, tal radicalidad se revela impracticable: no puedo dudar del hecho de que mientras estoy ejerciendo la duda, pienso; y entonces tampoco dudar de que, al menos mientras pienso, soy un ser pensante (res cogitans). A partir de esta certeza, y en contraste con ella, las cosas del mundo, el prójimo, Dios, se vuelven fantasmas meramente pensados por mí. Este es, en síntesis, el argumento. Como lo ha dramatizado Castelli, el problema es "que una vez que se entra en el laberinto de la conciencia, ya no es posible salir de él" (Enrico Castelli, 1956): el solipsismo como trágico destino del pensamiento subjetivista.

¿Cómo saber con evidencia cartesiana que a mis percepciones, a mis recuerdos, a mis deseos, corresponden entidades independientes de mi pensamiento? ¿Cómo saber con evidencia cartesiana que existen los otros? El filósofo francés se ve obligado a una suerte de malabarismo teológico en el intento de reponer la realidad del mundo de la res extensa. Pero la comunicación del pensamiento de un sujeto cogitante a otro ${ }^{31}$ sigue resultando un problema teóricamente insoluble porque no hay duda de que quien piensa y comunica algo a otro ser humano debe tener por evidente que existe aquel que lo escucha y tener por cierto, además, que su interlocutor es capaz de comprender en su propia intimidad, in auditu cordis, la palabra que el sujeto hablante le dice.

Tal es el supuesto irreductible por el que es 'alimentada' la comunicación, y es en tal convencimiento que me propongo comunicarle a otro lo que estoy diciendo, y por ello soy éticamente responsable de lo que digo. En pocas palabras, la confiabilidad del vínculo que establece un ser humano con otros, queda entregada a la palabra que se da y a la palabra que se recibe.

Por este motivo preferimos llamar sujeto testimonial al sujeto hablante, en el sentido de que es por medio de su acción comunicativa, cuando se hace explícita, que el sujeto testimonial quiere ex-ponerse en su verdadero ser ante el otro. O como diría el medioevo: por cuanto el verbum exterius que pronuncia el sujeto testimonia el verbum cordis o verbum interius que lo sostiene y fundamenta.

Para concluir este punto, 'veracidad' remite a una cualidad del sujeto veraz. 'Testimonio', en cambio, mueve a completar su sentido: se es testimonio ante otro sujeto, y de algo que 'actualmente' parece ser accesible a quien lo dice y no a quien lo escucha.

${ }^{31}$ De Descartes a sus lectores, por ejemplo. 
Pero tal vez esto no baste para asegurar al otro sujeto que las cosas son verdaderamente así: que el verbo exterior por el que nos presentamos exprese el verbum cordis que somos, que sea portavoz y expresión integra de él. Y eso es lo que pretende garantizar un sujeto cuando da explícitamente su palabra: que su palabra 'dada' tiene un valor de garantía en el tiempo, que no es un fenómeno fugaz, volátil, como el flatus vocis de los nominalistas.

\section{Promesa y testimonio}

En nuestros días, es la promesa el término más socorrido para garantizar de alguna manera una vinculación firme o, al menos, confiable entre los sujetos.

¿Qué es la promesa? Según su estructura prometer pertenece al grupo de las acciones que estamos examinando: aquellas cuyo cumplimiento como acción vinculante ocurre en el mismo momento en que el sujeto dice lo que dice, en este caso, 'te prometo' 32 .

Como ya tuvimos ocasión de precisar antes, el rasgo más propio de estas acciones comunicativas es, primero, su doble actualidad: temporal y performativa; luego, su carácter testimonial, y finalmente, su fuerza vinculante, rasgos que siempre se dan simultáneamente.

Pero otra cosa es el cumplimiento objetivo de lo ya prometido, la consumación en el mundo de lo que se debiera cumplir. Tal realización fáctica ocurre, siempre que ocurra, en un tiempo futuro convenido o meramente prudencial. Cabe insistir aquí que la acción comunicativa por su naturaleza de 'estar ocurriendo', de ser un presente — en el sentido más puntual posible_-, desplaza toda referencia a una temporalidad hacia atrás o hacia delante de la acción. En otros términos: la acción comunicativa se da siempre en el tiempo presente del sujeto que habla. Esta diferencia entre lo estructural y lo fáctico, que no siempre se tiene en cuenta, es esencial para ratificar el carácter propio y universal de las acciones comunicativas.

En el prometer, se comprende, no puede haber testimonio simultáneo al cumplimiento fáctico de lo que se promete, puesto que el testi-

32 'Prometer' pertenece a una familia de acciones comunicativas cuyo cumplimiento factual se fija en el futuro. A esta familia pertenecen también acciones como advertir, amenazar, vaticinar, etc. 
monio consiste en remitir a una experiencia actual ${ }^{33}$, y el cumplimiento fáctico de la promesa es, por el contrario, una aventurada apuesta respecto del futuro, contra las contingencias del mundo humano y del mundo natural, que pueden desbaratar lo prometido. Habrá que insistir en ello.

¿Qué puede testimoniarse de sí mismo?

Sin entrar en el tema escabroso del autoengaño, hemos dicho que para el sujeto de una acción comunicativa veraz, el verbum exterius que emite es portavoz y expresión íntegra de su verbum interius.

Con todo, suele ocurrir que el sujeto que habla en principio no explicite su acción testimonial, pero que luego considere oportuno detenerse en ella, declarándola, esto es, asumiendo el refuerzo testimonial de lo que ha dicho, prometiendo cuando se trata de una acción futura o 'dando su palabra' en otras referencias temporales de la vinculación ${ }^{34}$. Es decir, que confirme en primera persona la vinculación que pretende establecer con el otro sujeto al decirle lo que le dice.

La promesa, como declaración de lo que en un futuro se hará en pro del sujeto interactuante, es el caso más frecuente del re-forzamiento ${ }^{35}$ que se da a una acción comunicativa real.

Pero hemos visto que ni en esta ni en ninguna acción comunicativa puede darse testimonio de lo que todavía no $\mathrm{es}^{36}$; en este caso, del cumplimiento fáctico de la promesa. De tal manera que por el verbum exterius 'te prometo' solo se está testimoniando el propósito actual de realizar en el futuro una acción en pro del otro sujeto.

33 Todo testimoniar implica necesariamente el tener ahora una experiencia nítida e indubitable de eso que se testimonia.

34 Ejemplos: 'Vendré' (promesa implícita); 'Te prometo que vendré' (explícita); 'Yo estuve allí' (justificación implícita); 'Te doy mi palabra de que estuve allí' (justificación explícita).

${ }^{35}$ A propósito de este reforzamiento testimonial - que evoca en un sentido nuevo la fuerza ilocucionaria de Austin - parece discutible que la comunicación no asumida testimonialmente (el 'se dice' heideggeriano) sea la principal característica de la intercomunicación cotidiana. Frente a 'las contingencias de la vida', es al menos dudoso que el ser humano no deba asumir, incluso dramáticamente a veces, su condición de sujeto testimonial. Ante la posible observación de que prometer ante el juez no es algo que se hace en beneficio del juez, cabe responder que cuando se promete ante el juez no se le promete algo al juez sino al otro, ante el juez como testimonio legal.

${ }^{36} \mathrm{El}$ testimonio es de lo que ya se ha visto, oído o experimentado con la fuerza de una realidad indesmentible. 
Y aunque de hecho ocurre, no es lícito poner en duda gratuitamente ${ }^{37}$ la disposición que, actualmente, puede tener el sujeto que habla, a cumplir lo que está prometiendo. No obstante, es siempre lícito dudar de las posibilidades que tiene quien promete de cumplir eso que promete, ya sea a causa de las contingencias del mundo o de la vida humana $^{38}$, en particular, la de la muerte.

En otros términos, una promesa, explícitamente formulada, pretende enfatizar la seriedad y firmeza de ánimo con la que ahora el sujeto que tiene la palabra propone a otro una determinada 'cita en el mundo'. Sin embargo, el testimonio explícito de tal firmeza de ánimo, la palabra dada y el juramento, pueden ofrecerlo no solo respecto del futuro sino respecto de cualquier tiempo propio de la experiencia del sujeto que tiene la palabra.

En conclusión: la promesa, en cuanto ambigua apropiación de lo posible, tiene solo una fuerza testimonial limitada en comparación con la palabra que se da y con el juramento, con la diferencia de que en la primera no se especifica algo que es esencial en las otras: 'la prenda' que deja el sujeto al acreedor en resguardo del eventual incumplimiento de lo que está diciendo: su propia palabra ${ }^{39}$. Pero allí radica precisamente su valía. En su orfandad, sin nada que dar en prenda, y a contrapelo del mundo, la promesa se sobrevive a sí misma, en cuanto puro conato de ser, como el más heroico testimonio de sí.

En la convivencia humana los vínculos que se crean entre los individuos requieren en la mayoría de los casos de evidencias ${ }^{40}$ y de garantías inmediatas. En 'la palabra que se da' $-\mathrm{y}$ esto es esencial para un punto de vista ético- lo que ofrece el sujeto que tiene la palabra ${ }^{41}$ es entregar esa palabra en prenda como garantía del vínculo que ofrece y del crédito que obtiene. ¿Qué significa, entonces, esta entrega en

${ }^{37}$ No parece lícito enjuiciar la intimidad ajena y menos aún sin razón (véase Giannini, 2000).

${ }^{38}$ Aristóteles disculpa a quienes no cumplen su promesa cuando aparece alguna circunstancia que no está en el conocimiento actual de quien ha prometido. Pero pone una condición: que el agente de la promesa experimente pesar por lo ocurrido (Aristóteles, Eth. III, 2, 1110b20).

${ }^{39} \mathrm{La}$ antigüedad y popularidad de 'dar prenda' llegó desde el pasado hasta el juego de los niños.

40 Para la convivencia cotidiana, es evidente 'lo sensible inmediato', esto es, lo que se ve con 'nuestros propios ojos' y se toca con 'nuestras propias manos'.

${ }^{41}$ El sujeto ontológico. 
garantía de 'un fenómeno' que, en la expresión de Ricoeur, 'se esfuma, desaparece'?

Si es cierto que la palabra por la que un sujeto pro-pone un vínculo a otro sujeto, es expresión del testimonio que tal sujeto ofrece de sí mismo, entonces, dar esa palabra en garantía es jugarnos nuestra condición de sujetos testimoniales; esto es, lo que se juega es el derecho a volver a tener la palabra. Lo que se arriesga es quedar como un individuo 'sin palabra', ante aquellos a quienes se ha defraudado.

Un estigma terrible que nos cuesta vislumbrar en estos días en que nos parece que 'el habla habla' ${ }^{42}$; en una época en la que el discurso de la publicidad, de lo que 'se dice', tiene el favor en el oído de la mayoría. Un tiempo en el que el testimonio de sí —si es que se piensa en ello- recaería solo sobre las cosas que elegimos en el mundo, sobre lo que amamos o sobre lo que nos gusta, y no acerca del lazo que por la palabra vinculante mantenemos directamente con otros seres humanos, nexo en virtud del cual el ser externo aparece y 'funciona' como mundo.

Hay un ámbito de la realidad al que podemos referirnos y que otros sujetos siempre pueden más tarde verificar. Es el ámbito de la realidad física, de sus regularidades y de su efectivo acontecer. 'Verificar' aquí es comprobar intersubjetivamente la existencia del fenómeno enunciado o la reiteración de hechos específicamente similares en su estructura.

Incluso en el caso de la promesa de hacer algo, la verificación del cumplimiento fáctico es, ciertamente, algo que se puede comprobar y cuyo cumplimiento además se puede asegurar, como lo hace cotidianamente el comercio por ejemplo tomando una 'prenda', mueble o inmueble, en garantía.

Pero, ¿qué pasa en el campo de las intenciones, sentimientos, recuerdos, etc., que testificamos con la palabra pero que los fenómenos jamás podrían confirmar ni invalidar definitivamente a quien ha escuchado palabras como 'te quiero', 'te perdono', ‘jamás busqué recompensa ni honores...', 'no fueron esas mis intenciones...'? ¿Qué garantía es capaz de saciar una necesidad de verificación infinitamente más profunda que la científica o la comercial?

${ }^{42}$ Conocida expresión heideggeriana retomada también, como se sabe, por Lacan. 
El campo de las intenciones, de los sentimientos, de lo que pasa en la conciencia de cada cual, eso, es un ámbito inverificable, en el sentido de una verificación intersubjetiva.

Es por esta razón que en la comunicación cotidiana respecto de lo que a cada uno le pasa, de lo que cada cual desea, siente o piensa, los otros no tienen como garantía sino la palabra que cada cual quiere dar.

En conclusión: estamos necesariamente entregados a la palabra que de sí mismo da el otro.

Nuestra cultura actual, en la que se ha desvanecido el valor de la palabra testimonial, ha dejado escapar, por esto mismo, la certeza ética de que una palabra no solo dice algo del ser de las cosas del mundo, sino que esencialmente nos dice y nos expone a los otros.

\section{REFERENCIAS BIBLIOGRÁFICAS}

Aristóteles. Ética nicomaquea. Milano: Ed. Rizzoli, 1986.

Arendt, Hannat. La condición humana. Buenos Aires: Paidos, 2010.

Austin, John L. Cómo hacer cosas con palabras. Barcelona: Paidos, 1971.

Benveniste, Émile. Vocabulario de las instituciones indoeuropeas. Madrid: Ed. Taurus, 1983.

Calderón de la Barca. La vida es sueño. Santiago: Ed. Zig-Zag, 1950.

Castelli, Enrico. "Introduzione". Archivio di Filosofia, Padova, CEDAM, 1972. - L'indagine quotidiana, Roma: CEDAM, 1956.

Descartes, Renato. Meditaciones metafisicas. Buenos Aires: Sopena, 1946.

Derrida, Jacques. Limited Inc. París: Ed. Galilée, 1990.

D’Agostini, Francesca. De analíticos y continentales. Madrid: Ed. Cátedra, 2000.

Giannini, Humberto. Desde las palabras. Santiago: Ed. Univ. Católica, 1984. - La metafisica eres tú. Santiago: Ed. Catalonia, 2007.

- Del bien que se espera y del bien que se debe. Santiago: Dolmen, 2000.

Kierkegaard, Soren. Il concetto dell'angoscia. Firenze: Ed. Sansón, 1965.

Lévinas, Emanuele. Totalidad e infinito. Salamanca: Ed. Sígueme, 1987.

Platón. Alcibiades. Madrid: Biblioteca Clásica Gredos, 1997.

Ricoeur, Paul. "Ipseité, Altérité, Socialité". Archivio di Filosofia, Padova, CEDAM, 1986.

"Sentido y evento". Revista de Filosofia, Vol. XVII, Santiago, 1979.

Searle, John E. Actos de habla. Ensayo de filosofia del lenguaje. Madrid: Cátedra, 2001. 